\title{
DISASTER EMERGENCY RAPID ASSESSMENT BASED ON REMOTE SENSING AND BACKGROUND DATA
}

\author{
Xingyi $\mathrm{Han}^{1}, \mathrm{Jianjun}_{\mathrm{Wu}}{ }^{1}$ \\ 1. Faculty of Geographical Sciences, Beijing Normal University, Beijing, China (yixin_amine@mail.bnu.edu.cn)
}

Commission III, ICWG III/Iva

KEY WORDS: Rapid Assessment, Remote Sensing, GIS, Disaster

\begin{abstract}
:
The period from starting to the stable conditions is an important stage of disaster development. In addition to collecting and reporting information on disaster situations, remote sensing images by satellites and drones and monitoring results from disasterstricken areas should be obtained. Fusion of multi-source background data such as population, geography and topography, and remote sensing monitoring information can be used in geographic information system analysis to quickly and objectively assess the disaster information. According to the characteristics of different hazards, the models and methods driven by the rapid assessment of mission requirements are tested and screened. Based on remote sensing images, the features of exposures quickly determine disasteraffected areas and intensity levels, and extract key disaster information about affected hospitals and schools as well as cultivated land and crops, and make decisions after emergency response with visual assessment results.
\end{abstract}

\section{BACKGROUND}

Severe disasters are characterized by abrupt and dynamic changes, which the formation process and mechanism of them are complex. Therefore, the development of disaster monitoring and emergency response technologies based on scientific understanding of disaster mechanism and process is a key problem in the field. At present, key technologies that need to be solved include dynamic risk assessment techniques, and disaster damage vulnerability model-based disaster prediction and rapid assessment techniques.

The main assessment and decision-making emergency response work includes: building a disaster mechanism model for severe disasters, studying the stability changes of hazards, exposures and hazardous environments, and realizing disaster evolution simulation and risk dynamic assessment; using remote sensing data, historical cases, ground monitoring and statistical data to study disaster spatial statistical inference methods and hazard vulnerability models, and integrating background data and remote sensing monitoring results to achieve disaster progression and rapid assessment; based on public participation in disaster data, studying information fusion and geocoding techniques to identify the severity of the disaster and the affected target; evaluating the urgency and priority of emergency response based on the results of disaster assessment and assisting with crowdsourced disaster information, formulating material distribution and transportation plans, and optimize the resettlement of displaced persons plan and sort out the serial and parallel relationships of various emergency processes.

To construct a spatial database of historical disaster intensity and loss, study the spatial statistical reasoning technology based on the historical case database, and quickly assess possible disaster information. This paper focuses on constructing rapid assessment models based on background data in the disaster region with more detailed information on remote-sensing monitoring results to achieve progressive deduction and rapid assessment of disaster conditions. According to the characteristics of different hazards, the models and methods driven by the rapid assessment of mission requirements are tested and screened. Based on remote sensing images, the features of exposures quickly determine disaster-affected areas and intensity levels, and extract key disaster information about affected hospitals and schools as well as cultivated land and crops, and make decisions after emergency response with visual assessment results.

\section{RESEARCH AREA}

China has complex geographical and climatic conditions. Almost all of the natural disasters happen in every year, such as floods, droughts, earthquakes, typhoons, wind and hail, snowstorms, landslides and debris flows, as well as the disasters caused by modern volcanic activities, pests and diseases, forest fires. The recent severe events are earthquakes in Yushu (2010), Lushan (2013), Dingxi (2013), Ludian (2014), and floods in Northeastern (2013), Boyang (2016), etc. Natural disasters in China show obvious regional characteristics, prominent seasonal and stage features, and symbiotic disasters and associated significant characteristics.

\section{DATA}

\begin{tabular}{|c|c|}
\hline TYPE & FORM \\
\hline Disaster intensity & ShapeFile \\
Administrative division map & ShapeFile \\
Population density map & Tiff \\
Socioeconomic data & Txt \\
Building background data & ShapeFile \\
Monitoring results & Tiff \\
Observation data & \\
(temperature, sunshine hours, relative \\
humidity, wind speed, precipitation) \\
Soil type distribution (soil type \\
distribution map)
\end{tabular}

Table 1. Data Resources for Assessment 


\section{METHODOLOGY}

Drought, as a typical example, is a kind of non-abrupt and progressive disaster, which needs emergency response works when it happens with the meteorological conditions are predicted that would not relief the dryer situation. Therefore, the assessment of drought is mainly to evaluate the existing disaster situation dynamically. On the basis of remote sensing data, remote sensing data or products are used to monitor soil and vegetation water scarcity. Through appropriate regional drought index methods and models, such as SPI, SPEI, and CI, real-time analysis of drought and drought intensity is assessed. When individual indicators cannot objectively reflect the severity of drought, comprehensive indicators can be used to reflect drought conditions. When assessing the affected area of cultivated land and crops, the land use map of the cultivated area and the monitor drought index intensity map were superposed. Specifically expressed as:

Cultivated land distribution map $=$ Selection $\{$ land use first class classification map

Cultivated land damage map $=$ Drought intensity map/crop land distribution map

Areas Affected by Cultivated Land and Crops $=$ Calculated Area \{Plant Damaged Area Map\}

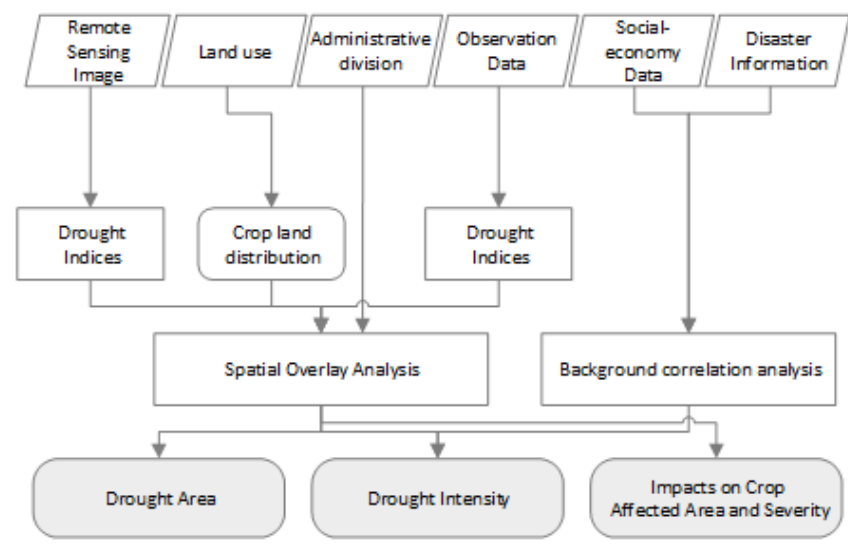

Figure 1. Flow chart of Methodology

\section{RESULTS AND DISCUSSION}

\subsection{Drought Area and Drought Intensity}

The period from 2007 to 2009 is one of the driest periods in China in the past 60 years. Long-term and high-intensity droughts occurred in northern North China, eastern Loess Plateau, central Inner Mongolia, and most of northeastern China Take the period from July 2007 to June 2008 as an example, in the above areas, the duration of drought lasted for more than 10 months.

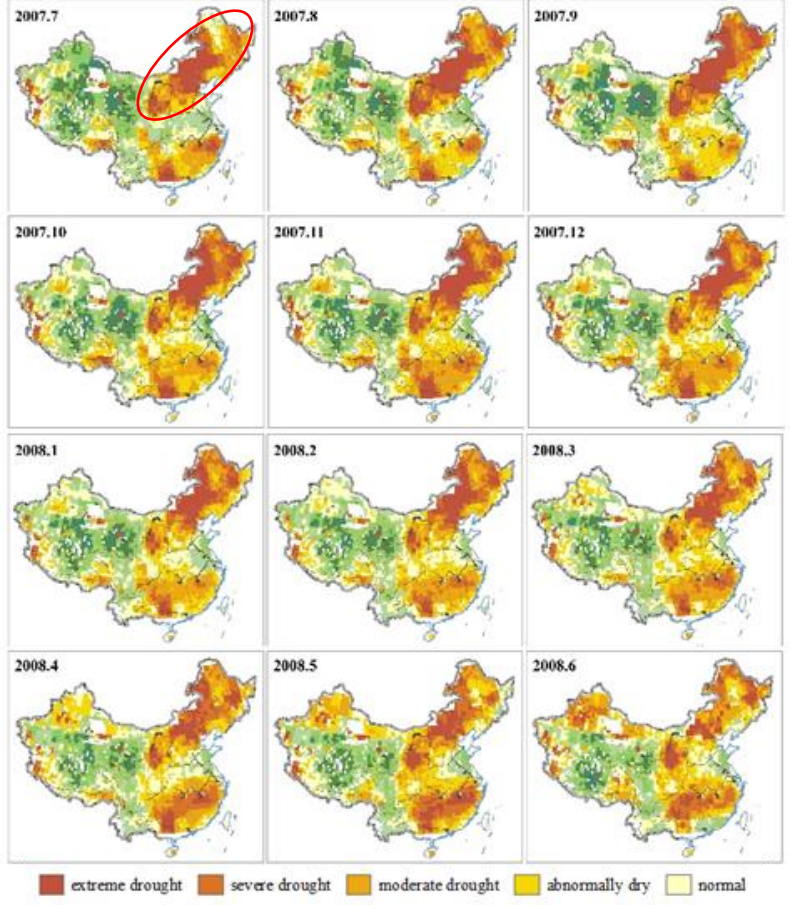

Figure 2. A Typical Drought Event

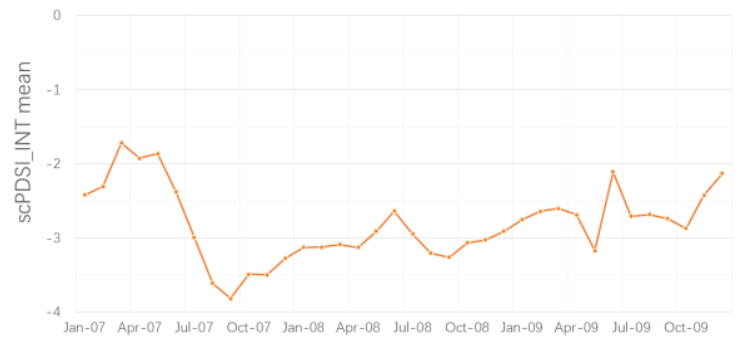

Figure 3. Drought Intensity in Drought Area

\subsection{Affected Crop Land Assessment}

Areas affected by drought are rich in land types, mainly arable land, grassland and forests. Affected grasslands are mainly distributed in most of Inner Mongolia, Hebei, northern Shanxi and western Liaoning. The affected arable land is distributed in the central and eastern regions of Heilongjiang Province and the southern regions of Hebei, Shanxi, and Shaanxi, and the affected forests are mainly distributed in Daxinganling Mountains and Changbai Mountain area.

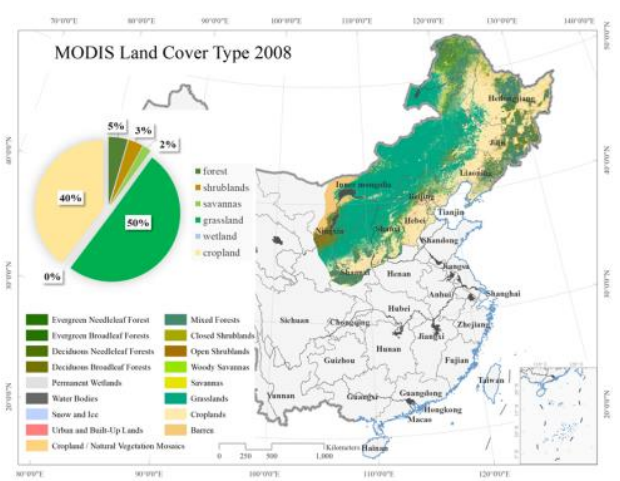

Figure 4. Land Cover Type in Drought Area 
The International Archives of the Photogrammetry, Remote Sensing and Spatial Information Sciences, Volume XLII-3, 2018

ISPRS TC III Mid-term Symposium "Developments, Technologies and Applications in Remote Sensing", 7-10 May, Beijing, China

\section{REFERENCES}

Kogan F N. 1990. Remote sensing of weather impacts on vegetation in non-homogeneous areas. International Journal of Remote Sensing, 11(8), pp. 1405-1419.

La-Chun W, Yun-Liang S H I. 2011. A Study on the Contents and Methods of Disaster Assessment. PROGRESS IN GEOGRAPHY, 20(2), pp. 122-130.

Lei T, Wu J, Li X, et al. 2015. A new framework for evaluating the impacts of drought on net primary productivity of grassland. Science of the Total Environment, 536, pp. 161-172.

Li B, Su H, Chen F, et al. 2013. The changing characteristics of drought in China from 1982 to 2005. Natural hazards, 68(2), pp. 723-743.

Wu J, Zhou L, Liu M, et al. 2013. Establishing and assessing the Integrated Surface Drought Index (ISDI) for agricultural drought monitoring in mid-eastern China. International Journal of Applied Earth Observation and Geoinformation, 23, pp. 397410.

Zhou L, Wu J, Hu T, et al. 2014. The investigation of relationship between integrated surface drought index (ISDI) detected drought condition and crop yield. In: Geoscience and Remote Sensing Symposium (IGARSS), 2014 IEEE International. IEEE, pp. 2050-2053. 